\title{
Software Agents and Contracts
}

Francisco Andrade

Universidade do Minho, Portugal

\section{Paulo Novais}

Universidade do Minho, Portugal

José Neves

Universidade do Minho, Portugal

\section{INTRODUCTION}

In the current economical context, characterized by the existence of a global society, the access to information is crucial for any economical and social development; yet, important technological challenges still remain. The representation, maintenance, and querying of information is a central part of this problem. How can we obtain the adequate information at the adequate time? How can we supply the correct items for the correct people at the correct time? How and where can we get the relevant information for a good decision-making? The organizations focus their competences in strategical areas and haverecourse to external supplies, cooperating with sporadic partners, with the objective of reducing costs, risks, and technological faults or maximizing benefits and business opportunities. One of the most radical and spectacular changes is the information dematerialization, the procedure automation, the recourse to decision support systems or intelligent systems, and to new forms of celebrating contracts (e.g., is it possible to practice commercial acts and celebrate deals using autonomous and pro-active computational agents?). The virtual organizations face new challenges and there must be a search for new answers to old questions. The negotiation processes through electronic means and the e-commerce platforms may set new forms of contracts, with engagements and negotiations among virtual entities.

Software agents are computational entities with a rich knowledge component, having sophisticated properties such as planning ability, reactivity, learning, cooperation, communication, and the possibility of argumentation. The use of the agent figure is particularly adequate to such problems. The objective is to build logical and computational models, as well as implementing them, having in consideration the law norms (i.e., legislation, doctrine, and jurisprudence).
Agent societies may mirror a great variety of human societies, such as commercial societies with emphasis to behavioral patterns, or even more complex ones, with pre-defined roles of engagement, obligations, contractual, and specific communication rules.

To begin with, it must be said that under western legal systems, computers totally lack legal personality (i.e., the possibility of being subjects of rights and obligations, of expressing a valid and binding will, of being liable for their own actions). However, intelligent artefacts are not only capable of acting according to its in-built knowledge and rules, but prove to be capable to learn from experience, modify its own states of knowledge, in particular according to cognitive, reactive and pro-active processes quite similar to those of the human beings.

Of course, the consideration of such behaviours and their role--the role of the computer is rapidly evolving from that of passive cipher to that of active participant in the trading process--operates a radical shift in the way we understand basic legal questions such as will and declaration, or the means of manifesting a will in order to get legal effects produced (Portuguese Civil Code, art. $217^{\circ}$ ), which leads us to an imperious need of analyzing the question of expression of consent in itself. And two main possibilities have been analyzed: the possibility of considering the electronic devices as mere machines or tools, used by its owner and the daring possibility of considering the electronic device as a legal person.

\section{LEGAL CONSIDERATION OF SOFTWARE AGENTS}

One possibility would be to consider the whole declarative process as indeed performed by a human. It would be like establishing a legal presumption that-Allen 
and Widdison call it a "legal fiction"! (1996, p. 43) - "all transactions entered into by the computer would be treated as transactions entered into by the human trader," thus putting the intention and the whole risk for the transactions "on the person best able to control them--those who program and control the computer" (Allenet al., 1996, p. 46, 49). This "fiction," based in a presumption that a person assents to a declaration or to a contract, even though he may not be aware that something was declared or that a contract was celebrated, would perfectly comply with the USA's UCITA regime (and intention), as it was pointed out by Jean-François Lerouge: "if a party creates a situation in which an electronic agent is to act on his behalf, then a party is bound by the actions of the "agents" (Lerouge, 2000). In this regard, Weitzenboeck speaks of attribution: "the operations of an intelligent agent are attributed to the human who uses the agent" (Weitzenboeck, 2001). That is to say that this theory recognizing that the only valid and relevant consent must be the one of the person on whose behalf the agent acts, a connection must thus be established between the action (non-human) and the intention (human), in a similar way to what appears to be a conclusive behaviour of the declarer in automatic inter-systemic electronic communications, such as EDI: " by initiating the electronic agent, the user is deemed to have accepted that contracts concluded by the agent will be binding on such user. The assent of the electronic agent will be inferred to be the assent of the (human) user of the agent" (Weitzenboeck, 2001). The acceptance of this theory would have an obvious impact--the risk of transactions would entirely be put "on the persons who program, control, or otherwise use an electronic agent" (Weitzenboeck, 2001) and these would eventually be assigned a sort of liability regime similar to the one relating to the use of cars or machines by the owner. "A party may be liable for a damage caused by an object." It is a well-known principle of Civil Law's liability regime that "a person to whose sphere machines can be assigned to is supposed to be liable for them. Thus, the one shall bear the risk that has the right and ability to control the machine and receives a (financial) benefit from its use" (Haentjens, 2002).

But wouldn't it be a terrible burden to put on programmers and users - who surely would not be "in such a condition to anticipate the contractual behaviour of the agent in all possible circumstances" and so would not be in position of "wanting" each and every "contract which the agent will conclude"? (Sartor, 2002)
Although this theory of considering electronic agents as a mere machines or tools is the most well accepted by legal authors, and besides it was contemplated by the US and Canada legislation, the truth is that some authors have been looking for other possible solutions, and the daring possibility of considering software agents as legal persons has been considered.

In order to evaluate the chances of attributing a legal personality to intelligent software agents, it might be interesting to analyze - establishing some due comparisons - the arguments that justified the consideration of corporate bodies as legal persons (Cunha, 1929).

In fact, legal persons are to be seen as a technical reality or instrument at the service of the law, through which it has achieved a way of dealing with certain human interests (Fernandes, 1996). Legal persons are thus considered a reality of the legal world corresponding to a social need, to a social interest worth of being dealt with, according to the law. Applying such considerations to intelligent software agents, it may be argued that those are physical and logical entities capable of multiple and autonomous intervention in the legal world, whose personification under the law might be foreseen as a technical way of responding to a social need - the need for more efficient and reliable ways of undertaking actions that man alone can not perform, or can not perform sufficiently and economically and in time.

Besides a own will, two basic requirements were enounced as needed for a corporate body to become a personality, and those were substratum (e.g., personal or patrimonial component, teleological component, intentional component) and recognition (Andrade, 1974). Does substratum exist in software agents? Can we consider its physical and logical structures as a personal or patrimonial element? Can we speak of teleological and intentional elements when referring to software? And how could recognition of legal personality to software substratum be handled?

The attribution of legal personality to intelligent software agents would have some obvious advantages: it would solve the question of consent and the validity of declarations and contracts enacted or concluded by software agents (Felliu, 2001); and it would reassure the owners-users of the agents about eventual liability concerns (Sartor, 2002). But it would also face several difficulties due to the intrinsic characteristics of software agents - some difficult problems could arise relating to questions such as domicile (Miglio, Onida, Romano, $\&$ Santoro, 2002) or patrimony (Weitzenboeck, 2001). 
And of course we must wonder whether electronic agents could or could not be liable for negligent acts or omissions, whether it is possible or not to consider them to act in good or bad faith (Miglio et al., 2002), whether or not it is possible to sue a software agent in court, or to impose sanctions on it (Andrade \& Neves, 2004).

The attribution of legal personality to electronic agents would require at least some sort of constitution/declaration act and eventually registration (Allen et al., 1996), in order to attribute a physical location to the agent, a minimum patrimony through a banking deposit or even a compulsory insurance regime, in order to fulfil financial obligations and liabilities. But even if all those difficulties could be overcome, would it be worth such a legal attribution? Or should we rather foresee the creation of special corporate bodies on whose behalf the electronic agents would act? Anyway, we must have a realistic approach to this issue, considering the challenging technical possibilities of software agents as entities requiring a particular new legal setting in order to enhance the full use of e-commerce in a global world.

\section{CONTRACT AND DECLARATION OF WILL}

Actually, to speak about contracts there must be two or more declarations of will containing a consensual agreement, consisting of an offer and of an acceptance. But agents operate in virtual entities without any direct intervention of humans, and they have a control on their own actions and on their own inner state (Ruggiero, 2003). So, legal difficulties obviously arise in such situations of contracting through the only intervention and interaction of autonomous intelligent systems, capable of acting, learning, modifying instructions, and taking decisions (Allen et al., 1996). Traditional legal principles have some difficulty to deal with the fact of agents celebrating contracts on their own. We must keep in mind that the used devices can act in such an autonomous way that it may have severe implications in the process of contract formation as we know it. Because intelligent artefacts will not only act according to their in-built knowledge and rules (Weitzenboeck, 2001) but they also will be able to learn from experience, modify its own behaviour according to cognitive, reactive, and pro-active processes quite similar to hu- man acting (Ruggiero, 2003). So, as Weitzenboeck puts it, "agreements will therefore no longer be generated through machines but by them, without any intervention or supervision of an individual" (Weitzenboeck, 2001). And since the program changes overtime without any human intervention, it would be very difficult to characterize it as the embodiment or expression of human intention" (Allen et al., 1996). This leads us to an imperious need of analyzing the question of expression of consent in transactions performed by agents. And two main possibilities have been analyzed: the possibility of considering these as mere machines or tools, used by its owner and the daring possibility of considering the agent as a legal person. The first perspective would be simpler to adopt and it seems in accordance with legislation already enacted in the United States and Canada: US Uniform Electronic Transactions Act (UETA), Uniform Computer Information Transactions Act (UCITA), and Canada's Uniform Electronic Commerce Act, which already expressly recognize that a contract may be formed by the interaction of electronic agents. The second possibility, although presenting some practical difficulties, may appear quite fascinating and must be considered. But, for the moment being it is not possible to consider the "electronic agents" as legal persons. Should we accept the fiction of considering them as mere tools the humans are using, even knowing humans may not be able to control them? Or is there another solution? For the time being, and considering that European jurisdictions have not yet decided what regime to adopt concerning electronic agents, it might be wiser to accept the suggestion of Sartor, of "...creating companies for online trading, which would use agents in doing their business. Such agents would act in the name of a company, their will would count as the will of the company, their legally relevant location would be the company's domicile, and creditors could sue the company for obligations contracted by those agents. The counterparties of an agent could then be warranted by the company capital, and the legal remedies available towards defaulting commercial companies" (Sartor, 2002).

But, even considering this, there must also be a link between the commercial act and the agents. Each agent must be identified (i.e., the agent must have access to a signature, for example, an electronic signature) certified by a trusted third party, that allows an electronic performance of the traditional functions of a signature, such as the identification of the signer, and the mani- 
festation of a will (Mireille \& Robert, 1998), in terms of assuring intention, authenticity and non-repudiation, and also of establishing integrity and certainty of the contents of the issued messages or declarations (Murray, 2003). The question here is that the agent is not yet a person. Can it therefore use an electronic signature of its own? For the moment being the point is doubtful (Martins, Marques, \& Dias, 2004). In order to avoid difficulties in law interpretation, it would be advisable that law clearly establishes the possibility for agents to use qualified electronic signatures, in order to enhance the use of agents in electronic commerce in a trustable and secure way.

\section{ISSUES OF PROOF}

Another important issue is certainly the one related to the proof value of such dematerialized informatics documents. Can these documents be admitted to prove a contract before the court, and if they can what will be its value? Under Portuguese law, the function of evidence is to create a firm belief in the reality of a fact. We know that contracts may be concluded by any means, except in certain situations when law requires a specific form or instrument. But, the general rule in Portuguese law is if the contract is not subject to a written form, also the proof can be done by any means. Documentary evidence is stated in article 362 of the Civil Code, which defines document as "any material object created by man capable of representing a fact, event, thing, or person." Under Portuguese law, electronic documents satisfy the requirement of written form when its contents are capable of being represented as a written declaration (art. $3 \mathrm{nr} 1$ Decree 62/2003) and when signed with a qualified electronic signature certified by an accredited certification authority, they will have the proof value of a private signed document (art. 3 nr. 2 Decree 62/2003). This kind of signature has the consequence of establishing a legal presumption that not only the signature was used with the intention of signing and that the document was not altered since then, but also that the person who used the signature is the holder of the signature or the legal representative of the company that holds the signature (art. $7 \mathrm{nr} .1$ Decree 62/2003). Once again, according to this article, it is quite doubtful that an agent would be considered as entitled to sign on behalf, for instance, of the company that owns the agent. In order to enhance the use of agents, law should be revised accordingly.
Yet, it is possible for parties using electronic agents to agree on a convention in order to establish the acceptance, in their relations, of the electronic documents as proofs of their transactions. The Portuguese Civil Code (art. 345) admits this kind of convention, with some exceptions (Mendes, 1991). Indeed, as it happens very often, and as it is suggested by Reed, "many of the potential problems, once they are properly identified, can be overcome quite simply through the mechanism of properly drafted contracts" (Reed, 1994). It is the will of the parties replacing law whenever law just ignores the reality and/or the actual needs of the commercial practice.

Related to the proof value of electronic documents appears the role, each day more and more important, of electronic evidence, in its broader sense, strongly related to the notion of traceability. As Overly refers, "Electronic documents may include word-processing files, spreadsheets, e-mail, records of instant messaging (IM) exchanges, Web pages, online order forms, databases, and digitized pictures, video, and audio files" (Overly, 2003). The idea is that electronic evidence will perform a more and more important role in the subject of proof of electronic contracts.

Also quite relevant for electronic contracting will be to establish the precise time when electronic communications really occurred. Time stamp services, determining the date and hour of an electronic operation (Eynde, 2001), will be of utmost importance.

\section{ELECTRONIC ARCHIVE AND ITS DIFFICULTIES}

Another issue should also be pointed out: in fact, legal systems should differentiate the various and quite different possibilities for electronic archiving (and, in terms of security or reliability, it is not exactly the same to record an electronic message in a cd-and there are cd's that can only be recorded once, or eventually, can be recorded many times, but leaving each time traces of the previous versions and of modifications - or in a floppy disk, in which the content would be much more volatile because it can be altered and re-recorded almost without leaving any trace). This kind of positive differentiation would have the big advantage of stimulating the use of the most advanced and secure archiving techniques and, after all, it would represent a tremendous advance in terms of reliability and security of transactions. And this would bring along big 
advantages in two different levels: security of the users and legal certainty. But of course this remark already indicates us a real need of analyzing the important issue of the existence of digital archive services and, eventually, of the need to have access to specialized services in the archival field performed by trusted third parties (Eynde, 2001). Without forgetting the technical difficulties related to the constant and quite fast evolution both in software as in hardware required to reading the archived electronic documents. Actually, these continual changes may even turn both software and hardware totally obsolete in just a few years (computer hardware and software are undergoing constant and rapid changes and nobody can foresee how electronic information will be processed 20 or 30 years from now (Dumortier, 2003)). So, it becomes critical to face new strategies allowing not just the electronic documents to be archived but also to be read at any time in the near future, whenever it may be required, within the legal prescribed time limits (How can we guarantee that the electronic documents that are being stored today will still be readable by the computers and programs that will be used in the future? (Dumortier, 2003)).. And the preservation of electronic documents, regardless of future software and hardware developments, must ensure the required proof of identification of the author of the document and the assurance of the document's integrity, having in mind the requirements of digital or dynamic signatures. Without this preservation and requirements the electronic commerce itself and the proof value of electronic documents would be seriously threatened (Caprioli \& Weisz, 2004)).

The debate about these issues - preservation and archive of electronic documents - is considering some possible strategies on solving the problems. These are mainly concerning two major options, or possible ways: emulation and migration (Eiteljorg, 1999).

Emulation intends to keep all electronic data in its original format, thus requiring that the original software and hardware be kept in such a way to permit the further reading of the documents at any time whenever required. Of course, this implies the maintenance of hardware and software systems for long periods of time (Dumortier, 2003).

Another possible solution would be reconverting every electronic document to new formats adapted to the new software and hardware standards adopted in commercial activities. Thus being, documents should have to be constantly transformed to new formats, in such a way to keep the content and enhance the reading upon the use of the new hardware and software programs (Dumortier, 2003). This strategy implies the so-called "migration" of electronic documents from one format to another.

The intervention of a trusted third party would allow the maintenance of a set of applications (hardware, software, operative systems) or at least the emulation of these programs in such a way to assure a further reading of documents generated upon these programs (Dumortier, 2003). But the maintenance of a very wide set of old applications would have an enormous cost, only possible for someone engaged in professionally assuring paid certification services (If one opts for a solution based on emulation, the trusted third party is even more essential. The costs and expertise required for this solution, requires that the task of archiving digital data will be appointed to an independent third party (Dumortier, 2003)). This would certainly be an important type of business to be developed within the information society.

Anyway, even in the eventuality of an option for the migration of documents, it would also obviously be mandatory that a trusted third party intervenes in order to assure that the "migrated" document - the one appearing at the end of a chain of transformed documents - is totally identical to the original in its contents and is authenticated as originated at the author of the original document (In the context of preservation based on migration the trusted third party is needed to keep track of the migration process and to make sure that the resulting document at the end of the migration chain keeps being trusted (Dumortier, 2003)).

The European directive on electronic signatures refers digital signatures certification services but not archival certification services (Dumortier, 2003). Also the main European laws on electronic documents and signatures worry mainly on the issue of the proof value of electronic documents but not with the most relevant issue of the ways and modalities of electronic archiving and not at all with the crucial issue of electronic archival services and of electronic archival certification (Caprioli et al., 2004). Yet, it is quite obvious that the validity of the electronic document itself must be connected to the technical aspects of electronic file maintenance and preservation. And it is also obvious that this subject has enormous legal implications, since only by keeping, accessing and assuring the integrity of electronic documents can we reasonably assure the 
Andrade F., Novais P., Neves J., Software Agents and Contracting, Encyclopedia of Networked and Virtual Organizations, Goran Putnik and Manual Cunha (Eds), Idea Group Reference, ISBN 978-1-59904-885-7, 2008. Software Agents and Contracts

legal security and proof value required for a secure electronic commerce (Sédallian, 2002).

\section{CONCLUSION}

The Virtual organizations scenarios bring along new challenges, consequently there is a need of searching for new answers to old questions. The negotiation processes through electronic means and the e-Business platforms may set new forms of contracts, with engagements and negotiations among virtual entities. Such engagements certainly require a new approach of contractual issues: the formation of contracts itself with a new analysis on will and declaration, but also the new ways of archiving and proving the electronic transactions.

In any circumstance, an ultimate choice must be done concerning the way we are to legally consider software agents, and the most realistic options are to view them as mere machines or tools, to consider them as legal persons, or to create online companies for online trading through software agents. In any case, issues of signature and of proof will also have to be reconsidered, in order to enhance software agents participation in electronic transactions. And the quite relevant (and challenging) issue of electronic archiving must be deeply studied, both form a technical and from a legal perspective, in order to assure full compliance with legal requirements and a high level of security in electronic contracting. And these are essential issues to be faced if we want to enhance virtual organizations in electronic commerce.

\section{REFERENCES}

Allen, T., \& Widdison, R. (1996). Can computer make contracts? Harvard Journal of Law and Technology, 9(1).

Andrade, F., \& Neves, J. (2004). Intelligent electronic inter-systemic contracting-issues on consent and contract formation. In Proceedings of the $6^{\text {th }}$ International Conference on Enterprise Information Systems - ICEIS 2004, Porto, Portugal.

Andrade, M. (1974). Teoria Geral da Relação Jurídica. Coimbra Editora, I, 56-57
Caprioli, E., \& Weisz, G., (2004). Archivage électronique: Des contraintes juridiques et technologiques, Le Journal du Net.

Cunha, G. (1929). Tratado de Direito Civil-Em comentário ao Código Civil Português. Coimbra Editora, $I, 422$

Dumortier, J. (2003). E-government and digital preservation. E-Government: Legal, Technical and Pedagogical Aspects, Publicaciones del Seminario de Informatica y Derecho, Universidad de Zaragoza (pp. 93-104).

Eiteljorg, H. (1999). Preservation for the future--with emulation or migration? CSA Newsletter, XII(1).

Eynde, S., (2001). Wat archiveren en hoe? Op zoek naar de rol van PKI voor digitale archieven," nota 7 , in ICRI, Leven.

Felliu, S. (2001). Intelligent agents and consumer protection. International Journal of Law and Information Technology Online, 9, 235-248.

Fernandes, L. A. C. (1996). Teoria Geral do Direito Civil, vols. I e II, $2^{\mathrm{a}}$ edição, Lex, Lisboa.

Haentjens, O. V. (2002). Shopping agents and their legal implications regarding Austrian law. In Proceedings of LEA-2002-The Law of Electronic Agents. Bologna.

Lerouge, J. F. (2000). The use of electronic agents questioned under contractual law. Suggested solutions on a European and American level. The John Marshall Journal of Computer and Information Law, 18(2), 403-433

Martins, A., Marques, J., \& Dias, P. (2004). Cyberlaw em Portugal, CentroAtlantico.pt.

Mendes A., (1991). Valor Probatório dos Documentos Emitidos por Computador, Procuradoria Geral da República, Gabinete de Documentação e Direito Comparado. Colóquio Informática e Tribunais, Lisboa.

Miglio, F., Onida, T., Romano, F., \& Santoro, S. (2002). Electronic Agents and the Law of Agency in Atti del Convegno "The Law of Electronic Agents-Selected Revised Papers, Bologna.

Mireille, A., \& Robert, D., (1998). Pistes de réflexion pour une législation relative à la signature digitale et au régime des autorités de certification. In Revue Générale de Droit Civil, 4, 285-310. 
Murray, J. (2003). Public key infrastructure digital signatures and systematic risk. The Journal of Information, Law, and Technology (1).

Overly, M. (2003). Overly on electronic evidence in California. Thomson-West.

Reed, C. (1994). Advising clients on EDI contracts. Computer Law and Practice, 10(E).

Ruggiero, E. (2003). Il contratto telematico, Edizioni Simone, 2003.

Sartor, G. (2002). Agents in Cyberlaw. In Proceedings of the Workshop on the Law of Electronic Agents (LEA 2002).

Sédallian, V.(2002).L'archivage del'acte électronique, Juriscom.net.

Weitzenboeck, E. (2001). Electronic agents and the formation of contracts. International Journal of Law and Information Technology, 9(3), 204-234

\section{KEY TERMS}

Agents: Encapsulated computer systems that are situated in some environment and are capable of flexible, action in that environment in order to meet their objectives.

Archive: Conservation of documents in order to ensure the possibilities of proof.

Contract: Voluntary and licit human fact, formed by two or more declarations converging on the production of legal effects according to the manifested will.

Declaration: Behaviour which, externally observed, appears as manifestation of a certain will.

Legal Person: Entity capable of being subject of rights and obligations

Proof: Demonstration of the invoked "truth."

Will: Volition, normally (but not always) coincident with the objective sense of the declaration. 